\title{
Physical Fitness Profiles of Sitting Volleyball Players of the Turkish National Team
}

\author{
Mehmet Fatih Yüksel ${ }^{1, *}$, Tarık Sevindi ${ }^{2}$ \\ ${ }^{1}$ Faculty of Education, Necmettin Erbakan University, Konya, Turkey \\ ${ }^{2}$ Faculty of Sports Science, Aksaray University, Aksaray, Turkey
}

Copyright $\odot 2018$ by authors, all rights reserved. Authors agree that this article remains permanently open access under the terms of the Creative Commons Attribution License 4.0 International License

\begin{abstract}
This research is conducted to determine the physical profiles of sitting volleyball players of the Turkish National Team. 12 male players from Turkish Sitting Volleyball National Team volunteered to participate in the study. The anthropometric measurements were taken over dominant extremity. In order to determine the physical features of the participants tests and measurements were made regarding stature, bodyweight, BMI, upper body length, upper extremity length, arm length, forearm length, hand length, arm circumference, forearm circumference, upper body length, modified sit-ups, modified abdominal endurance, modified push-ups, hand grasping power, plate tapping, and shoulder flexibility. SPSS 21.0 program was used in the analysis of the data, and minimum, maximum, arithmetic mean, and standard deviation values were determined. As a conclusion, it can be mentioned that the anthropometric measurements of the players and modified bio-motor test results of the disabled individuals will inspire the sports scientists/trainers and this data are vital with regards to selection of the players.
\end{abstract}

Keywords Sitting Volleyball, Physically Disabled, Physical Features

\section{Introduction}

Professional disabled sport has developed rapidly in recent years. Sport is crucial with regards to helping disabled individuals coming out of social isolation. Disabled individuals with a growing number include not only people born with disabilities, but also many victims of traffic accidents and war conflicts [1]. Physical activities of the disabled individuals are not limited to leisure time activities or forms of rehabilitation that improve their physical fitness. Being a part of active rehabilitation, sport aims to restore self-confidence of the disabled. Sport is an important means for that purpose. Competitive sport is also a way of satisfying ambitions, presenting high abilities and even competing with able-bodied people [1-5]. Today, there are numerous sport branches adapted for the disabled individuals. Sitting volleyball is one of the Paralympic sport branches that the disabled can participate.

As a high-level competitive sport, sitting volleyball appeared on the international scene comparatively late, in 1980. That year sitting volleyball became an official event for the first time at the Paralympic Games in Arnhem, The Netherlands [6, 7]. We follow the FIVB (Federation Internationale de Volleyball) rules, with additions from the WOVD (World Organization Volleyball for Disabled) rules and regulations for sitting volleyball. Some characteristics of the game/court: the playing court is a 10 $\mathrm{m}$ by $6 \mathrm{~m}$ rectangle; the attack line is $2 \mathrm{~m}$ away from the center line axis; the net, which is $0.80 \mathrm{~m}$ by $6.50 \mathrm{~m}$, is placed vertically over the center line and is $1.15 \mathrm{~m}$ high with regards to men's standards; players use hands for moving and sweeping on the court; buttocks must remain on the floor while playing the ball; block on the service is allowed; for official tournaments a classification on minimum disability is required $[1,6,8]$.

Sitting volleyball is a sport activity that provides evident positive effects during rehabilitation and general resocialization of the individuals with physical disability [9]. Sitting volleyball requires moving on the floor by using hands and quick reactions for getting into position early enough to play effectively. This requires sufficient practice on basic techniques, plenty of play-time experience, and development of hand-eye-body coordination. For a successful sitting volleyball on elementary level, basic skills must be acquired [8]. Consisting of quick moves and stimuli-responsive reactions, sitting volleyball has a dynamic character, and it is evaluated that the physical fitness of an athlete will be a major factor for success.

This research was carried out in order to examine the physical fitness levels of Turkish National Team sitting volleyball athletes. 


\section{Materials and Methods}

\subsection{Ethical Scope and Official Permits}

Written permit for the study was obtained from "Necmettin Erbakan University, Meram Medical Faculty, Ethics Committee of non-Pharmaceuticals and non-Medical Device Researches" with the decision dated 12/01/2017 and numbered 2017/1107. Necessary permissions for conducting tests and measurements were taken from the Turkey Physically Disabled Sports Federation. All the volunteers participating in the research signed the informed consent (volunteer) form and completed a personal information form.

\subsection{Study Group}

The subjects of this research were chosen among the volunteer players. 12 male players participated in the research from Turkish Sitting Volleyball National Team.

All of the measurements and tests of the volleyball players composing the experiment group were carried out in Paralympic camp training center (Aksaray/Turkey). Disability classification of the players was determined before the tests and measurements. When the disability conditions of the participant players were examined the figures below were detected;

Disability condition: congenital $(\mathrm{n}=6)$, acquired $(\mathrm{n}=6)$;

Disability type: poliomyelitis $(\mathrm{n}=3)$, lower extremity unilateral amputated $(n=2)$, coxae peccetur $(n=2)$, CMT (Charcot-Marie-Tooth) syndrome $(\mathrm{n}=1)$ and Les autres $(\mathrm{n}=3)$;

Mobilization Type: prosthesis $(n=2)$, orthesis $(n=1)$, crutch $(\mathrm{n}=1)$, and independent $(\mathrm{n}=8)$.

Some limitations were applied considering the physical disability condition during the tests and measurements. Anthropometric measurements were conducted on dominant extremities. Hand grasping power and plate tapping values of a player were not determined due to a problem in the non-dominant hand. The tests and protocols that were conducted to determine the physical features of the players are explained below.

\subsection{Data Collection Tools}

Height and Body weight: In the linear measurements a tapeline with $0.01 \mathrm{~m}$ sensitivity score was used. Weight measurements were made with a digital weighing scale with a sensitivity level of $0.01 \mathrm{~kg}$ [10].

Body mass index: Using body weights and lengths, BMI was determined using the BMI = Body weight / (Length) ${ }^{2}$ formula [10].

Trunk length, upper extremity length, arm length, forearm length, hand length, arm circumference and forearm circumference measurements were made with tape and recorded in $\mathrm{cm}[11,12]$.
Trunk length: Determined by measuring the distance between the $\mathrm{C} 7$ and the coccyx.

Upper extremity length: Determined by measuring the distance between the Acromion and the tip of the longest finger on the hand.

Arm length: Determined by measuring the distance between the acromion and the olecranon while the shoulder and the arm were loose.

Forearm length: Determined by measuring the distance between the olecranon and styloid protrusion of radius.

Hand length: Determined by measuring the distance between the styloid protrusion of radius and the tip of the longest finger on the hand.

Arm circumference: Determined by locating the middle point of the distance between the acromion and olecranon, and measured while the muscles were loose.

Forearm circumference: Determined by locating the most swollen point of the muscle, and measured while the arm was loose.

Modified functional reaching test: The test was used in order to evaluate trunk balance. The players positioned in a posture that the hip-knee is in flexion position, upper body is in a vertical $90^{\circ}$ position, leaning to back support of the chair, and there is $5 \mathrm{~cm}$ in between popliteal fossa and the side of the chair. Lower extremities were fastened to each other on the femur shaft distal. The players were sat on high chairs in order to prevent foot support. The players were asked to do $90^{\circ}$ shoulder flexion. The length of the arm was marked on the ulnar styloid level and the player was asked to reach out to front as much as possible. During the reaching activity, compensation mechanisms were avoided such as shoulder protraction and neck flexion. The length of the distance that ulnar styloid moved was marked on the maximal reaching point, and the distance in between the first and the second values was recorded in $\mathrm{cm}$ [13].

Modified Sit-up Test: The player positions himself lying on his back on the mat, knees bent, soles of the feet fully on the mat, hands on each side of the hips, and fingers in extension on the mat. The legs were supported as to keep the knees bent. The individual was asked for arising until the scapula bottom level, and do as many sit-ups as he could in 30 seconds $[14,15]$.

Modified abdominal endurance: Lying on his back on the mat, the individual was asked for arising until scapula bottom level and keep this position as much as he could. The time was stopped and recorded, as the participant touched the scapula bottom level or deformed the position [16].

Modified push up test: The participant was positioned as face down on the mat, and the modified push-up version for the females was applied. The power of upper extremity muscles of the subject and the number of rearward moves of upper body was recorded [16].

Hand grasping strength: Beginning from the right hand, the measurement was made with Jamar brand dynamometer and recorded in $\mathrm{kg}$, while the subject was on 
foot, arm straight with a $10-15^{\circ}$ angle from the shoulder on one side [17].

Plate tapping test: It was applied to measure the arm move speed. Two plastic discs (A and B) were placed on the table, $80 \mathrm{~cm}$ away from each other. Subject touched A, and B discs 25 times (totally 50) with the dominant hand as fast as possible. The timekeeper started as the subject touched disc A, and the value obtained at the end of the test was recorded in seconds [18].

Shoulder Flexibility: It was measured with Back Scratch Test. The players were sat in a position that their backs were vertical. The players were asked to bond their hands at the back while one of their shoulders were respectively in flexion, abduction, external rotation and elbow flexion; and the other shoulders were in extension, adduction, and internal rotation and elbow flexion. In this phase, the distances between the $2^{\text {nd }}$ fingers were recorded in $\mathrm{cm}$. If the fingers are touching each other the value is 0 , otherwise the distance was recorded in minus $\mathrm{cm}$. The measurement was repeated after the positions of the extremities were changed and the results were recorded in $\mathrm{cm}$ as well [18].

\subsection{Analyzing of Data}

SPSS 21.0 program was used in the analysis of the data obtained in the study and minimum, maximum, arithmetic mean, and standard deviation values were determined.

\section{Results}

Table 1. Average physical features of the sitting volleyball players.

\begin{tabular}{|c|c|c|c|c|c|}
\hline VARIABLES & $\mathrm{n}$ & Min & Max & Mean & S. D. \\
\hline Age (year) & 12 & 14,00 & 44,00 & 28,00 & 12,25 \\
\hline Training age (year) & 12 & 1,00 & 10,00 & 2,54 & 2,42 \\
\hline Height (cm) & 12 & 163,00 & 201,00 & 180,16 & 11,61 \\
\hline Weight (kg) & 12 & 55,00 & 102,00 & 77,70 & 13,66 \\
\hline BMI (kg/m $\left.{ }^{2}\right)$ & 12 & 18,59 & 28,67 & 23,84 & 2,78 \\
\hline Trunk length (cm) & 12 & 45,00 & 64,00 & 54,58 & 7,00 \\
\hline Upper extremity length (cm) & 12 & 74,50 & 97,00 & 84,50 & 5,53 \\
\hline Arm length (cm) & 12 & 29,00 & 41,50 & 35,20 & 3,03 \\
\hline Forearm length (cm) & 12 & 25,00 & 32,00 & 28,33 & 1,95 \\
\hline Hand length (cm) & 12 & 18,50 & 23,50 & 20,95 & 1,37 \\
\hline Arm circumference (cm) & 12 & 27,50 & 42,50 & 32,37 & 4,06 \\
\hline Forearm circumference (cm) & 12 & 23,00 & 38,50 & 28,75 & 3,65 \\
\hline Trunk balance (cm) & 12 & 21,00 & 64,00 & 45,00 & 13,50 \\
\hline Modified sit-up (number) & 12 & 31,00 & 50,00 & 39,08 & 6,57 \\
\hline Modified abdominal endurance (s) & 12 & 45,00 & 307,00 & 126,41 & 75,53 \\
\hline Modified push up (number) & 12 & 17,00 & 54,00 & 39,16 & 10,43 \\
\hline $\begin{array}{c}\text { Dominant hand grasping strength } \\
\text { (kg) }\end{array}$ & 12 & 34,00 & 67,00 & 53,08 & 11,93 \\
\hline $\begin{array}{c}\text { Non-dominant hand grasping } \\
\text { strength (kg) }\end{array}$ & 11 & 32,00 & 67,00 & 50,63 & 11,03 \\
\hline Dominant hand plate tapping (s) & 12 & 7,68 & 14,40 & 9,78 & 1,86 \\
\hline $\begin{array}{c}\text { Non-dominant hand plate tapping } \\
\text { (s) }\end{array}$ & 11 & 9,09 & 14,09 & 11,12 & 1,94 \\
\hline Right shoulder flexibility (cm) & 12 & $-5,00$ & 24,00 & 8,31 & 7,58 \\
\hline Left shoulder flexibility (cm) & 12 & $-7,00$ & 16,50 & 3,86 & 8,05 \\
\hline
\end{tabular}

\section{Discussion and Conclusions}

This research is conducted to determine the physical profiles of sitting volleyball players of the Turkish National Team. Bringing some preliminary values obtained in the research into the literature, it was aimed to create a reference guide for the trainers, sport scientists and other shareholders. In context of the literature review completed, no researches were found regarding determining the physical and bio-motor features of the sitting volleyball players in Turkish national team. Therefore, the findings of this study will be useful and assessable for this sports branch and others. Within the context of the research, some tests and measurements were determined regarding stature, bodyweight, BMI, upper body length, upper extremity length, arm length, forearm length, hand length, arm circumference, forearm circumference, upper body length, modified sit-ups, modified abdominal endurance, modified push-ups, hand grasping power, plate tapping, and shoulder flexibility.

In a study conducted to determine the anthropometric profiles of sitting volleyball players, the averages of the right and left arm lengths of the players were respectively 30,21 and $30,77 \mathrm{~cm}$, while right and left forearm length averages were 21,30 and $21,98 \mathrm{~cm}$, and right and left hand length averages were reported as 13,44 and 13,69 $\mathrm{cm}[20]$. In our research, it was observed that the upper extremity length values (respectively averages $35,20 \mathrm{~cm}, 28,33 \mathrm{~cm}$, $20,95 \mathrm{~cm}$ ) were higher. This difference is considered to be stemmed from the study group's being elite level players and being composed of national team level players. Moreover İnce et al. [20] reported that arm length is not a disadvantage for the disabled since the height of the net is lower. However, although the height of the net is lower, considering the characteristics of the game, since failure to contact either buttocks to the ground is forbidden by rule, we are of the opinion that both upper extremities and upper body height is vital in all parts of the game, particularly in offence and block positions, and they are important criteria in selection of the players. This determination is supported by the research conducted by $[9,21]$.

A research was reported to be conducted by Mahmutovic et al. [9] to determine the effects of morphological features of the sitting volleyball players in Bosnia Herzegovina Premier League on conditional-motor skills. According to the results of the research, it was reported that the players with longer arm lengths, wider pelvis width and upper arm circumference, and lower abdominal skinfold values have an advantage in application of conditional-motor features and morphological measurements were dominant in sitting volleyball. The findings of that research verify the determinations obtained by Mahmutovic et al. [9].

In a study conducted to determine the relation between the anthropometric variables of 20 elite level Polish sitting volleyball players and anaerobic power, field tests, and 
game performances, it was reported that the physical fitness and game performances are dependent on the anthropometric variables of the players [21]. Hasanbegovic et al. [22] reported that they determined the effects of trainings in sitting volleyball on motor skills by factor analysis. It was mentioned that the explosive power factors of the participants are important at the initial measurements; however, after the training processes, motor skills primarily develop, rendering mobility and agility the basic component. Although the researches [9, $21,22]$ include important correlations and useful information regarding anthropometric and motor performances of the players, it was observed that they did not provide any averages regarding neither anthropometric nor motor performances. In this respect, this research differs from the existing ones with regards to its findings providing average values. This data are considered to provide contribution to form the standards with regards to sitting volleyball and similar disabled sports branches.

In a research in Egypt, Amgad [23] reported that a weight-lifting training composed of 8 moves was applied to sitting volleyball players during 12 weeks, 3 days a week, and 60 minutes a day. At the end of the study, it was reported that the training had statistically significantly increased the strength of the arm muscles and had a positive effect. In another research on amputated football players, it was reported that there was a positive correlation between stabilization of the upper body muscles and upper body flexor strength, and it was suggested that upper body stabilization, balance, and upper body muscle strength trainings must be included in the training plans [24]. When the findings obtained by the researchers are examined, it was evaluated that the balance and strength of upper bodies of the sitting volleyball players of Turkish national team are sufficient; however, the abdominal endurance level should be developed. The dominant hand grasping power values (average 53,08 $\mathrm{kg}$ ) and non-dominant hand grasping values (average $50,63 \mathrm{~kg}$ ) detected during the research are considered to be quite high. Those high values verify the determinations of Amgad [23] and Aytar et al. [24] which stated that training had a positive effect on muscle development.

With regards to the types of disability, it was observed that the players of this research composed of minimal disabled $(n=2)$ and disabled $(n=10)$ individuals, which was not a homogenous group. It is a known fact that these players have varied pathologies differentiating their functional levels and their functional features could vary despite having similar disabilities. In this respect, since the study was conducted on sitting volleyball players of Turkish national team and the participants were limited to 12 , being unable to classify considering disability conditions or being unable to carry out statistical analyses based on disability conditions could be accepted as a weakness of the research. However, in a research conducted on 128 male and 91 female sitting volleyball players, Marszalek et al. [25], it was reported that there was no difference regarding game efficiency among both male and female players who had different types of disability. In their research, it was observed that Morres et al. [26] had focused on the relation between the sports performances (service, reception, set, attack, block, and defense) and classification system (disability, minimal disability). It was mentioned that the disability levels of the participant athletes did not decrease their performances. Similarly, Vute [7], Hayrinen and Blomqvist [27], Hayrinen et al. [28], Protic and Valkova [29] had conducted studies based on game efficiency of sitting volleyball. It was understood that game analyses were done in order to evaluate the game performances, thus the motivational factors behind participation in the sitting volleyball were examined, and the researchers focused on game variables in these researches. Therefore, it can be mentioned that it is a necessity that more comprehensive researches be conducted based on disability classification and functional features of the volleyball players.

Moving in complete independency is vital for a physically disabled individual. When disabled individuals who deal or do not deal with sports are compared, it is stated that the ones dealing with sports are more independent in daily life in terms of mobility, have higher social participation, and have higher life quality compared to individuals who do not deal with sports. Moreover, reported that regular exercises of a disabled individual were effective on physical fitness [30-32].

Considering the available data in literature, there were limited number of researches on sitting volleyball players and particularly the physical features of Turkish national team level players were not determined, which motivated this research to be carried out. In this regard, being the first analysis on the physical features of sitting volleyball players of Turkish national team and having reached to some significant findings could be accepted as the strength of the research, and the obtained findings could be accepted as preliminary figures. Additionally, it is considered that more comprehensive researches on sitting volleyball with higher participant player figures and particularly with field studies can provide findings that will fill the located gaps in this field. And the measurements obtained should be supported by technique evaluations such as attack, block, serve, and receive in order to make holistic assessments.

As a conclusion, the anthropometric measurements and modified bio-motor test results with regards to the disabled individuals of this research, which is the first study conducted on sitting volleyball Turkish national team, are vital since they provide usable data in player selection for the sports scientists/trainers and other shareholders. 


\section{REFERENCES}

[1] J. Wieczorek, A. Wieczorek, L. Jadczak, R. Sliwowski, M. Pietrzak. Physical activity and injuries and overstraining syndromes in sitting volleyball players, Stud Physical Cult Tourism, Vol.14, 299-305, 2007.

[2] D. Danis, W. Mikuła. Injuries and overstraining syndromes in wheelchair basketball players, Medycyna Sportowa, Vol.12, No.101, 15-17, 1999.

[3] F. Di Russo, A. Bultrini, S. Brunelli, A.S. Delussu, L. Polidori, F. Taddei, M. Traballesi, D. Spinelli. Benefits of sports participation for executive function in disabled athletes, Journal of Neurotrauma, Vol.27, No.12, 2309-2319, 2010 .

[4] Y. Hutzler, A. Chacham-Guber, S. Reiter. Psychosocial effects of reverse-integrated basketball activity compared to separate and no physical activity in young people with physical disability, Res Dev Disabil, Vol.34, No.1, 579-587, 2013.

[5] D. R. Shapiro, J. J. Martin. Athletic identity, affect, and peer relations in youth athletes with physical disabilities, Disabil Health J, Vol.3, No.2, 79-85, 2010.

[6] K. Akasaka, S. Kusano, M. Yamamoto, K. Takahashi. SF-36 Health survey in disabled sitting volleyball players in Japan, J Phys Ther Sci, Vol.15, No.2, 71-73, 2003.

[7] R. Vute. Scoring skills performances of the top international men's sitting volleyball teams, Gymnica, Vol.29, No.2, 55-62, 1999.

[8] R. Vute. Teaching and coaching volleyball for the disabled: foundation course handbook ( $\left.2^{\text {nd }} E d\right)$, Faculty of Education, University of Ljubljana, Ljubljana, 2009.

[9] I. Mahmutovic, S. Delalic, S. Uslu, M. Ibrahimovic, A. Tabakovic. Impact of morphological characteristics on the situational-motor abilities of sitting volleyball players, International Journal of Science Culture and Sport, Vol.3, No.1, 29-33, 2015.

[10] E. Zorba, Ö. Saygın. Fiziksel Aktivite ve Fiziksel Uygunluk. (2. Bask1), İnceler Ofset, İstanbul, 2009.

[11] R. Easterby, K. H. E. Kroemer, D. B. Chaffin. (Ed). Anthropometry and Biomechanics, Plenum Press, New York and London, 1982.

[12] A. S. Otman, H. Demirel, A. Sade. Tedavi Hareketlerinde Temel Değerlendirme Prensipleri, Hacettepe Üniversitesi Fizik Tedavi ve Rehabilitasyon Yüksekokulu Yayınları, Ankara, 1995.

[13] N. Özünlü, N. Ergun. Trunk balance assessment in wheelchair basketball players, Fizyoter Rehabil, Vol.23, No.1, 44-50, 2012.

[14] M. E. Sahlberg, U. Svantesson, E. M. Thomas, B. Strandvik. Muscular strength and function in patients with cystic fibrosis, Chest, Vol.127, No.5, 1587-1592, 2005.

[15] D. Tomchuk. Companion Guide to Measurement and Evaluation for Kinesiology, Jones \& Bartlett Learning, Canada, 2011.

[16] N. Ergun, G. Baltacı. Spor Yaralanmalarında Fiztoyetrapi ve
Rehabilitasyon Prensipleri (2. bask1), Hacettepe Üniversitesi Fizik Tedavi ve Rehabilitasyon Yüksekokulu Yayınları, Ankara, 2006.

[17] M. Günay, K. Tamer, İ. Cicioğlu. Spor Fizyolojisi ve Performans Ölçümü (3. Bask1), Gazi Kitabevi, Ankara, 2013.

[18] C. Adam. Eurofit: handbook for the Eurofit tests of physical fitness, Italian National Olympic Committee, Central Direction for Sport's Technical Activities Documentation and Information Division, Rome, 1988.

[19] S. Dewhurst, T. M. Bampouras. Intraday reliability and sensitivity of four functional ability tests in older Women, Am J Phys Med Rehabil, Vol.93, No.8, 703-707, 2014.

[20] G. İnce, C. Şen, C. Türkeri, E. Kızılkanat, S. Özandaç. Oturarak voleybol Türkiye şampiyonasına katılan erkek sporcularin antropometrik profillerinin belirlenmesi. II. Ulusal Engelli Bireyler İçin Fiziksel Aktivite Çalıştayı, Çanakkale, 2010.

[21] J. Marszalek, B. Molik, M. A. Gomez, K. Skucas, J. Lencse-Mucha, W. Rekowski, V. Pokvytyte, I. Rutkowska, K. Kazmierska-Kowalewska. Relationships between anaerobic performance, field tests and game performance of sitting volleyball players, Journal of Human Kinetics, Vol.48, 25-32, 2015.

[22] S. Hasanbegovic, S. Ahmetovic, S. Dautbasic. Effects of programmed training on motor abilities of persons with movement impairment in sitting volleyball, Homo Sporticus, Vol.13, No.1, 68-71, 2011.

[23] A. L. I. Amgad. The impact of weight training on the defensive performances for the sitting volleyball players (Amputees), World Journal of Sport Sciences, Vol.3, 1146-1150, 2010.

[24] [24] A. Aytar, N. O. Pekyavas, N. Ergun, M. Karatas. Is there a relationship between core stability, balance and strength in amputee soccer players? A pilot study, Prosthet Orthot Int, Vol.36, No.3, 332-338, 2012.

[25] J. Marszalek, B. Molik, M. A. Gomez. Game efficiency of elite male sitting volleyball players with regard to athletes' physical impairment, International Journal of Sports Science \& Coaching, https://doi.org/10.1177/1747954117716791, 2017.

[26] I. Morres, P. Mustafin, C. H. Katsis, E. Koutsi, C. H. Milanese, G. Papaioannou. Sitting-Volleyball Medical Classification System. Contradictions \& Recommendations towards the Sport-Specific Classification Principles, [in:] Abstract booklet of VITA Conference IPC "Classification-solution for the future", 17-18, 2006.

[27] M. Hayrinen, M. Blomqvist. Match analysis of elite sitting volleyball. Research Institute for Olympic Sports, KIHU. Retrievedfrom:https://www.researchgate.net/profile/Mikko Haeyrinen/publication/271208323 Match analysis in elit e_sitting_volleyball/links/54c1fe31 $\overline{0} \mathrm{cf} 25 \mathrm{~b} 4 \overline{\mathrm{b}} 8072 \mathrm{~b} 201$. $\overline{\mathrm{pdf}}$, 2006.

[28] M. Hayrinen, M. Blomqvist, H. Lehto, S. Heino. Match analysis of women's sitting volleyball at international level. European Congress of Adapted Physical Activity (EUCAPA), Jyväskylä, 2010. 
[29] M. Protic, H. Valkova. Psychosocial aspects of player's engagement to the sitting volleyball, Acta Kinesiologica, Vol.5, No.2, 12-16, 2011

[30] Y. Hutzler, S. Ochana, R. Bolotin, E. Kalina. Aerobic and anaerobic arm-cranking power outputs of males with lower limb impairments: relationship with sport participation intensity, age, impairment and functional Classification, Spinal Cord, Vol.36, No.3, 205-12, 1998.
[31] B. Wilhite, J. Shank. In praise of sport: promoting sport participation as a mechanism of health among persons with a disability, Disabil Health J, Vol.2, No.3, 116-127, 2009.

[32] K. Yazıcıŏlu, F. Yavuz, A. S. Göktepe, A. K. Tan Influence of adapted sports on quality of life and life satisfaction in sport participants and non-sport participants with physical disabilities, Disabil Health J, Vol.5, No.4, 249-253, 2012. 